\title{
Temporal arteritis
}

\section{Occurrence of ocular complications 7 years after diagnosis}

\author{
JAMES F. GULLEN \\ Department of Ophthalmology, University of Edinburgh, and Royal Infirmary of Edinburgh
}

One of the major problems in the management of patients with temporal arteritis, particularly those in whom loss of vision in one eye has already occurred, is to decide for how long corticosteroid therapy should be continued.

The following case report is presented because it suggests that the disease process may remain active for a very long time, in this instance 7 years, and even then, despite treatment, complete immunity from complications cannot be assured.

\section{Case report}

April, 1964

A music teacher, aged 64 years, came to the Eye Department because of severe frontal headache of 3 weeks' duration. Because of tenderness in the temples a diagnosis of temporal arteritis was suspected and this was confirmed by temporal artery biopsy. The erythrocyte sedimentation rate was $83 \mathrm{~mm}$. in the first hour. There were no ocular symptoms, visual acuity was $6 / 6$ and $\mathrm{N}_{5}$ in each eye, and examination of the eyes revealed no abnormality. Treatment with prednisolone was instituted and brought about a complete remission of symptoms.

$1964-1965$

In the course of the ensuing 18 months the dose of prednisolone was maintained between 10 and $20 \mathrm{mg}$. daily depending on the erythrocyte sedimentation rate which was taken at monthly intervals. In November, 1964 , this had risen to $90 \mathrm{~mm}$. and in September, 1965, a reading of $105 \mathrm{~mm}$. in the first hour was obtained. On these occasions the dosage was increased until the level fell again although readings under $40 \mathrm{~mm}$. were never attained over this whole period.

In October, 1965, temporal artery biopsies were taken from each temple and showed no evidence of active disease. Full medical investigation was also carried out at this stage and no other disease process was identified.

1966-1970

Prednisolone therapy was continued during this period but erythrocyte sedimentation rate readings of over $80 \mathrm{~mm}$. were recorded on a number of occasions in 1966 and 1967 . By 1968 , readings around $40-50 \mathrm{~mm}$. were usual, but eventually in 1969 a maintenance dose of $5 \mathrm{mg}$. daily was achieved, the erythrocyte sedimentation rate at this stage usually remaining under $40 \mathrm{~mm}$.

February, $197 \mathrm{I}$

The patient presented as an emergency because of visual loss in the right eye of 6 hours' duration. The visual acuity had dropped to 6/60 and Ni8; the pupil reaction was not impaired but the disc 
was hyperaemic and swollen on the temporal side (Fig. I). The visual field (Fig. 2) showed a dense central scotoma. The erythrocyte sedimentation rate was $45 \mathrm{~mm}$. in the first hour. Right temporal artery biopsy showed no evidence of active arteritis. Intravenous fluorescein angiography showed normal choroidal filling and a normal fluorescein run. There was, however, increased
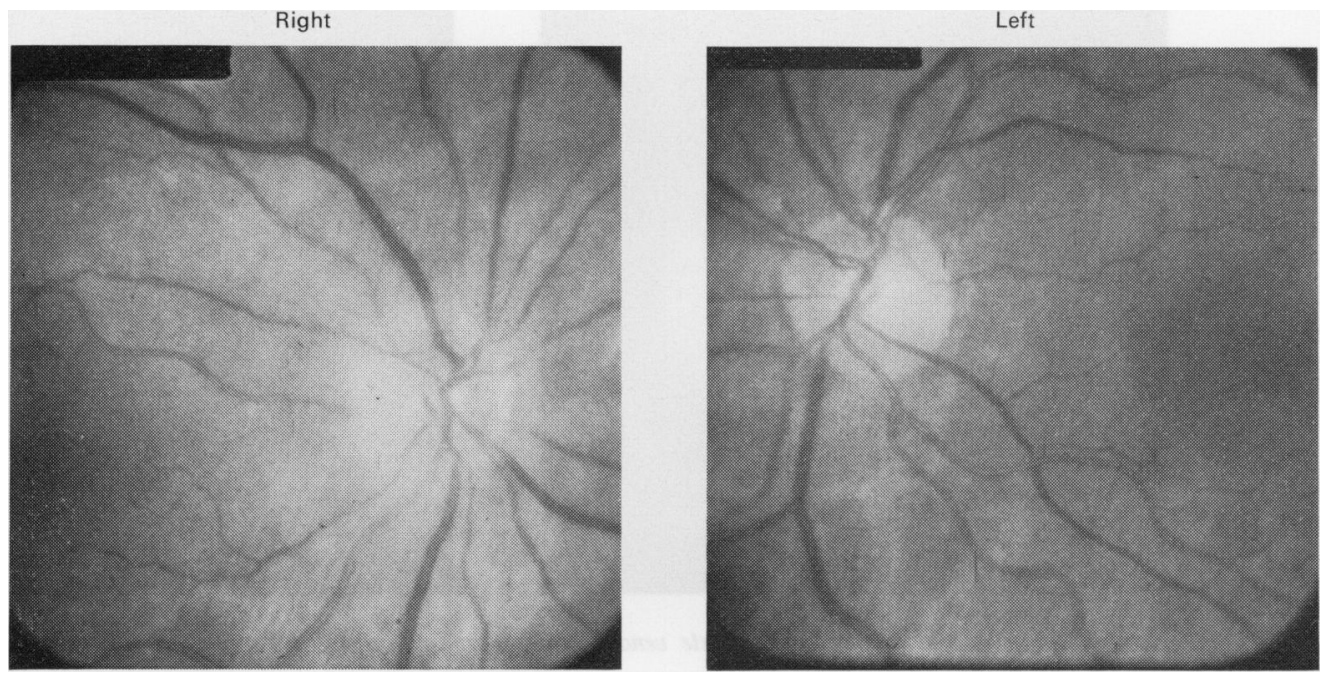

F IG. I Hyperaemic swollen right optic disc compared to normal left disc

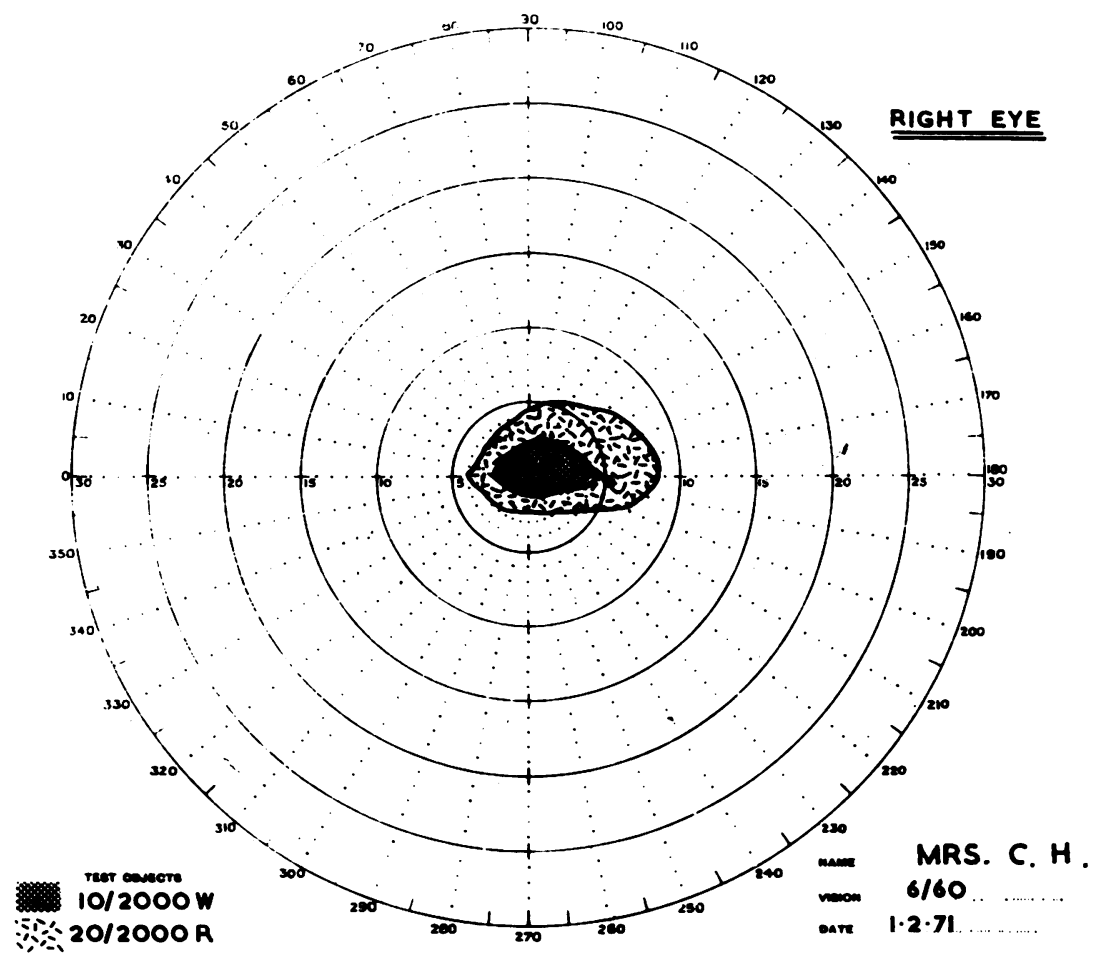

FIG. 2 Right visual field at onset showing dense central scotoma 
late fluorescence of the affected right nerve head (Fig. 3). A diagnosis of ischaemic optic neuropathy was proposed. The corticosteroid therapy was immediately stepped up and ACTH was also given.
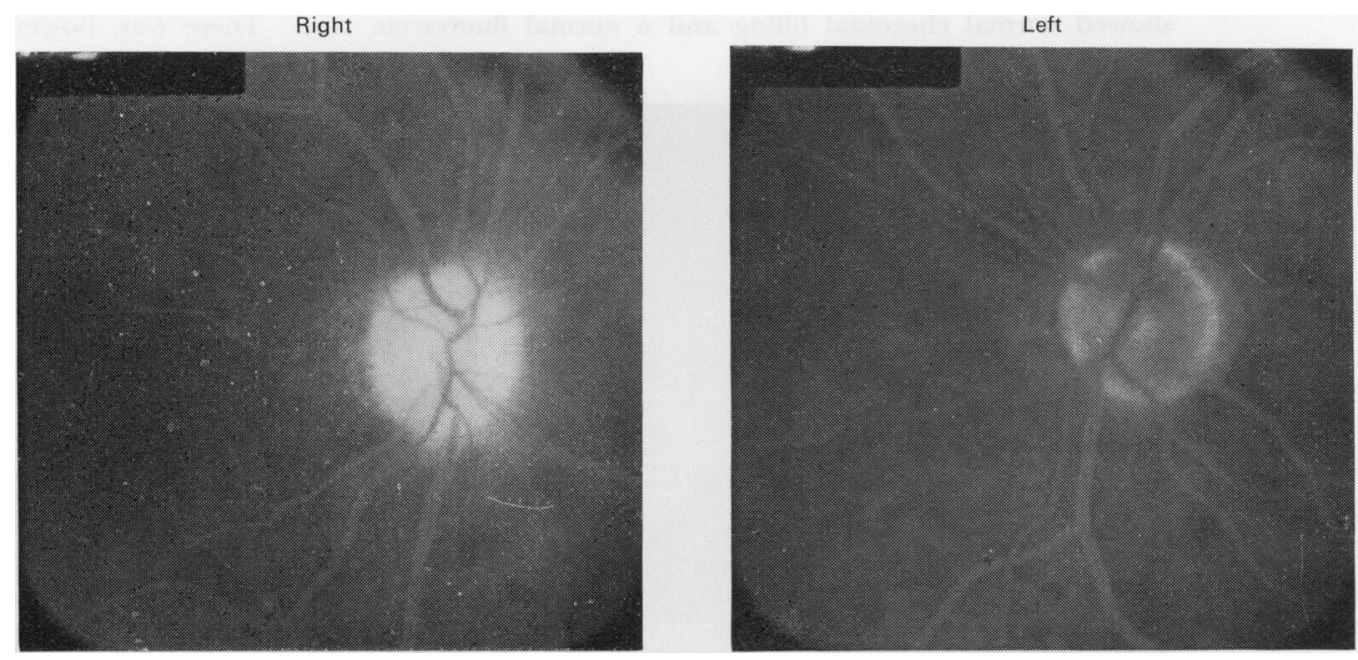

FIG. 3 Fluorescein angiograms in late venous phase showing increased fluorescence of right disc compared t.) normal left disc

In the course of the following month the swelling and hyperaemia of the disc subsided but no improvement in visual acuity was recorded. An erythrocyte sedimentation rate of $60 \mathrm{~mm}$. was obtained in March, 1971, but by June, readings of around $20 \mathrm{~mm}$. were regularly obtained and the dose of prednisolone was gradually reduced to ro $\mathrm{mg}$. daily. By now the right disc was uniformly pale and the vision remained around $4 / 60$ to $6 / 60$ and $\mathrm{N}_{1} 8$. The field defect had contracted to that shown in Fig. 4 (opposite). This altitudinal type of scotomatous defect is characteristic of a vascular lesion in the optic nerve.

\section{Discussion}

The self-limiting nature of the disease known as temporal, cranial, or giant cell arteritis is stressed in most text-books of medicine, e.g. Davidson ( I966) stated that it usually ended in recovery after several months Cecil and Loeb (1959) considered that it was a self-limiting disease lasting for from 2 to 30 months. Parsons-Smith (1959), in his series of fifty patients with cranial arteritis who attended an Eye Hospital, found that the course of the illness extended in most cases over a period of about 3 months. Miller (1964) quoted the case of a patient with temporal arteritis in whom ocular complications occurred while he was still receiving treatment 3 years after diagnosis. The present author (Cullen, 1963, 1967) has also reported cases in which the eyes have become involved after too early withdrawal or reduction of corticosteroid medication. The first of these cases is of particular importance in that the ocular involvement was minimal, showing a central scotoma similar to that reported above. Substantial or total visual loss is, however, the rule in this condition (Cullen, i 967 ).

In an attempt to determine the activity of the disease in the superficial temporal vessels, we have performed repeated biopsies on a number of patients followed-up over long periods in whom the diagnosis was confirmed initially by a positive temporal artery biopsy. Repeat biopsies taken at 3 and 6 months have always given positive results. At I2, 


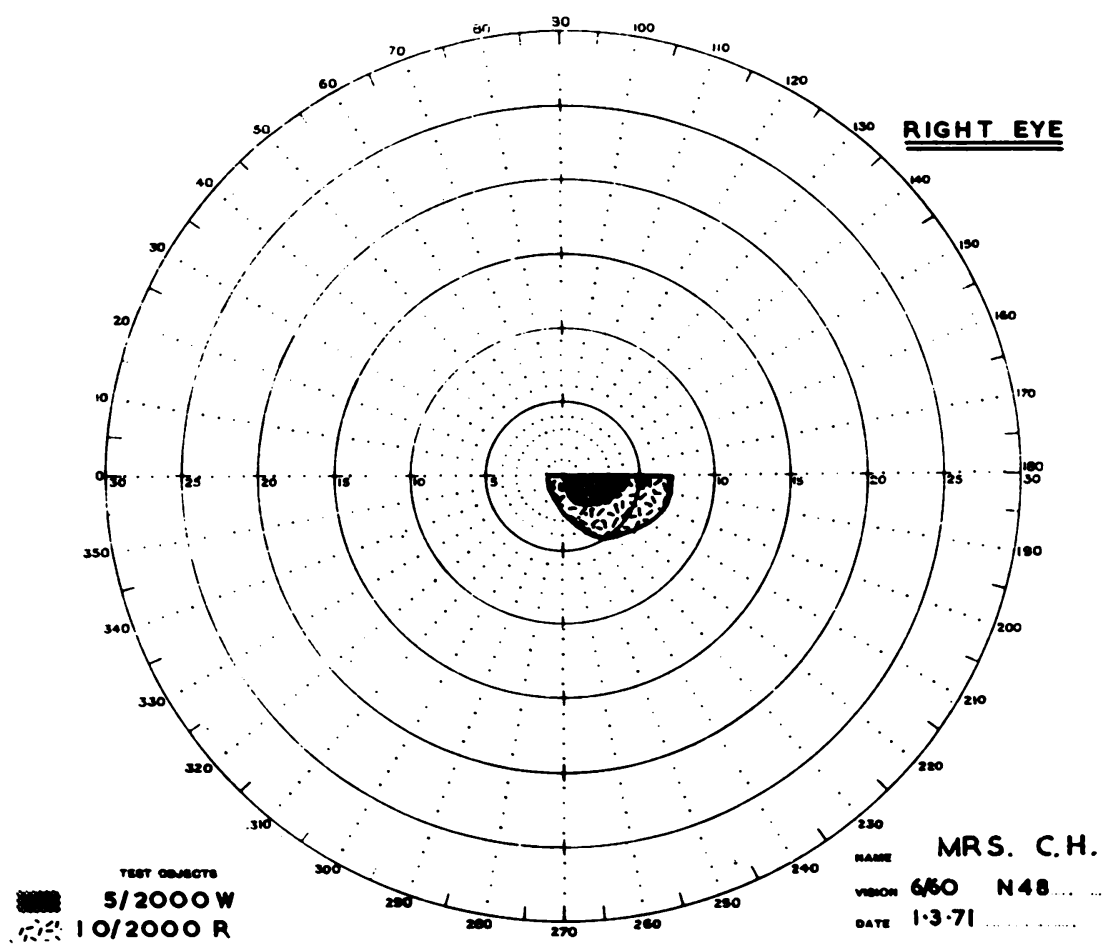

FIG. 4 Right visual field showing altitudinal type scotoma

I 8 , and 24 months we have had negative repeat biopsies, but in other cases repeated biopsies at I2, 2I, and 26 months have still shown evidence of active arteritis. It must be emphasized, however, that even though the condition may be inactive in the superficial temporal vessels, this does not necessarily mean that active inflammation is not present elsewhere in the carotid system, particularly in the posterior ciliary arteries.

The customary guide to the duration of therapy has, in the past, been the erythrocyte sedimentation rate readings and the principle of therapy has been to try to withdraw treatment when the erythrocyte sedimentation rate remains normal on attempted withdrawal. In this context we can assume that an erythrocyte sedimentation rate of up to $40 \mathrm{~mm}$. can be considered normal in elderly patients, as suggested by the surveys of Boyd and Hoffbrand (1966) and Bottiger and Svedberg (1967). In the present case report the high erythrocyte sedimentation rate levels despite continuing treatment over 7 years and particularly during the first 3 to 4 years must be considered significant and indicative of active disease, even though repeated biopsies, which were taken 18 months after the initial diagnosis, showed no evidence of active arteritis.

In the case reported here, it could be argued that the ocular involvement might be due to a cause other than temporal or giant cell arteritis. Acute optic or retrobulbar neuritis associated with demyelinating disease would be unusual in this age group and recovery of vision would have been expected. Arterio-sclerotic ischaemic optic neuropathy is, of course, a more likely possibility, although in this particular patient there was no other evidence of systemic or vascular disease and repeated blood pressure recordings had never given readings above 150 systolic or 100 diastolic. In the series of cases of non-arteritic 
ischaemic optic neuropathy reported by Foulds ( 1969 ), nineteen of his 2 I patients showed evidence of other diseases and had normal erythrocyte sedimentation rates, and in this group the prognosis for return of vision after corticosteroid therapy was good.

The evidence that the optic nerve involvement in the patient reported above was due to arteritis is supported by the continued elevation of the erythrocyte sedimentation rate over a very long period, the classical clinical picture and course of the ocular symptomatology as seen in other treated cases, and, in particular, the initial pathological evidence of active arteritis in the superficial temporal vessels. Without pathological examination of the posterior ciliary arteries themselves, however, a definite conclusive diagnosis could not be made.

\section{Summary}

A case of temporal arteritis is presented, in which ocular complications occurred 7 years after the initial diagnosis. The problems of treatment in this disease and the duration of treatment are discussed.

\section{References}

BOtTIGER, L. E., and SVEDBERG, c. A. (1967) Brit. med. J., 2, 85

BOYD, R. V., and HOFFBRAND, B. I. (1966) Ibid., r, $90 \mathrm{I}$

CECIL, R. L., and LOEB, R. F. (1959) "A Textbook of Medicine", roth ed. Saunders, Philadelphia and London

CUlleN, J. F. (1963) Trans. ophthal. Soc. U.K., 83, 725

- (1967) Ibid., 87, 759

Davidson, L. S. P. (1966) "The Principles and Practice of Medicine", 8th ed. Livingstone, Edinburgh

FOULDS, w. S. (1969) In "William Mackenzie Centenary Symposium on The Ocular Circulation in

Health and Disease", ed. J. S. Cant, p. 136 . Kimpton, London

MILleR, H. (1964) Trans. ophthal. Soc. U.K., 84, 627

PARSONS-SMITH, G. (1959) Brit. F. Ophthal., 43, 204 